\title{
What Controls Recent Changes in the Circulation of the Southern Hemisphere: Polar Stratospheric or Equatorial Surface Temperatures?
}

\author{
Isidoro Orlanski \\ Atmospheric and Ocean Science Program, Princeton University, Princeton, USA \\ Email: orlanski@princeton.edu
}

Received July 30, 2013; revised August 28, 2013; accepted September 4, 2013

Copyright (C) 2013 Isidoro Orlanski. This is an open access article distributed under the Creative Commons Attribution License, which permits unrestricted use, distribution, and reproduction in any medium, provided the original work is properly cited.

\begin{abstract}
Recent research suggests that both tropical ocean warming and stratospheric temperature anomalies due to ozone depletion have led to a poleward displacement of the mid- and high-latitude circulation of the Southern Hemisphere over the past century. In this study, we attempt to distinguish the influences of ocean warming and stratospheric cooling trends on seasonal changes of both the zonally symmetric and asymmetric components of the southern hemisphere circulation. Our analysis makes use of three data sets-the ERA40 reanalysis and results from two different runs of the GFDL global atmosphere and land model (AM2.1) for the period 1870 to 2004. A regression analysis was applied to two variables in each of the three data sets-the zonal component of the surface wind $\mathrm{U}(10 \mathrm{~m})$ and the height at $300 \mathrm{hPa}$ - to determine their correlation with zonally averaged polar stratospheric temperatures (T_polar-at $150 \mathrm{hPa}$, averaged over a band from $70 \mathrm{~S}-80 \mathrm{~S}$ ) and low-level equatorial temperatures ( $\mathrm{T}$ equator - at $850 \mathrm{hPa}$ averaged over a band at $5 \mathrm{~S}-5 \mathrm{~N}$ ). Our analysis shows that the zonally symmetric surface winds have a considerably enhanced intensity in high latitudes of the southern hemisphere over the summer period, and that the stratospheric temperature trend, and thus ozone depletion, is the dominant contributor to that change. However, the climatic change of the asymmetric component of zonal wind component at $\mathrm{z}=10 \mathrm{~m}$ (U10) as well as of $300 \mathrm{hPa}$ heights has been found to be large for both summer and winter periods. Our regression results show that correlation with T_equator (our proxy for global warming) explains most of the climatic changes for the asymmetric component of $\mathrm{U} 10$ and $300 \mathrm{hPa}$ heights for summer and winter periods, suggesting the influence of warming of the global oceans on anticyclones south of the Indian Ocean and south-eastern Pacific Ocean.
\end{abstract}

Keywords: Southern Hemisphere Changes; Ozone Depletion; Ocean Warming; Poleward Stormtrack

\section{Introduction}

The polar displacement of the mid- and high-latitude circulation of the Southern Hemisphere over the last decades of the past century has been reported in a large number of articles. An observed polar shift of the surface westerlies derived from reanalysis [1,2], among others) has been verified with radiosonde observations [3] as well as satellite observations [4]. This trend of the positive phase of the Southern Hemisphere Annular Mode (SAM) has been also identified in simulations of the last century as well as projections of future climate change. The trend of the positive phase of the SAM index implies a poleward shift of many different components of the Southern Hemisphere middle and higher latitude circulation, including storm tracks [2] and the southern edge of the Hadley Circulation $[5,6]$.

A number of regional climate changes over the middle and high latitudes of the SH have also been observed over the past century that seem to show the impact of the asymmetric component of the westerlies. Regional studies have shown a strong seasonal impact in precipitation over the middle latitudes of the SH [7,8]). For example, as the average surface air temperature of Australia increased by $0.7^{\circ} \mathrm{C}$ over the past century, there have been marked declines in regional precipitation, particularly along the east and west coasts of the continent $([9,10]$. Considerable regional changes which have also been observed over Antarctica-strong warming trends were reported over the west Antarctic region, but there was no significant change over the rest of the continent $[3,11$ 14]). Although there is some evidence of a correlation of 
trends of the Antarctic Peninsula and the zonally symmetric component of the SAM [1,3], recent results indicate that recent warming has not been restricted to the Antarctic Peninsula, but has been significant across the entire west Antarctica ice sheet [15], (hereafter HR2010); [16]. Also the seasonal pattern of warming is not consistent with a response to SAM trends [14]. Moreover, HR2010 and [16] concluded that the month-to-month variability pattern of the zonally asymmetric SH troposphere is rather dominated by two-quasi-stationary anticyclones in the western section of the Southern Ocean. They stress that the importance of these anticyclones has a profound effect on the climate of the sub-polar regions of the SH by affecting the sea-ice variability and blocking the eddy activity of the storm track.

Much research concerning the SH zonally asymmetric circulation has focused on the Pacific-South American mode (PSA, e.g, [17]) or the major zonal waves. However, these large-scale decompositions may mask important local variability. In HR2010, the month-to-month variability explained by the zonal waves 1 and 3 was examined, and an alternative representation of the $\mathrm{SH}$ circulation was suggested based on two quasi-stationary anticyclones in the sub-Antarctic western hemisphere. These anticyclones are related to the zonal waves, but as HR2010 stresses, features of their variability are masked by the zonal wave decomposition; in particular, the anticyclones' strengths are not positively covariant. HR2010 also shows that they capture variance independent of the Southern Annular Mode and explain a generally greater fraction of the variability than the PSA.

The importance of stratospheric ozone depletion on the atmospheric circulation of the troposphere has previously been studied with an atmospheric general circulation model (e.g., [18]). Their focus was the relative importance of ozone depletion contrasted with that of increased greenhouse gases and accompanying sea surface temperature changes. By specifying ozone and greenhouse gases forcing independently, and performing long, timeslice integrations, they concluded that the impacts of ozone depletion are roughly 2 - 3 times larger than those associated with increased greenhouse gases, for the Southern Hemisphere tropospheric summer circulation. However, the [18] study mainly focuses on the zonally symmetric circulation.

By recognizing the importance of both the symmetric and asymmetric components for climate change, the purpose of this work is to identify the respective roles of tropical ocean warming and the cooling trend of stratospheric temperatures anomalies due to ozone depletion on the seasonal changes in both symmetrical and asymmetrical components of the southern hemisphere circulation, with particular emphasis on the lower and upper tropospheric circulation. The limitations of observed and model data are a major challenge to determine how climate warming and ozone depletion have affected the South hemisphere circulation (the issue of the quality of data used in this analysis will be discussed below in "Data and methods"). However, a relevant and related question that can be answered is how polar stratospheric temperature trends and surface equatorial temperature trends could affect circulation changes in the southern hemisphere.

Our simple approach is to consider the zonally symmetric component as the zonal average of the variable and the asymmetric part as the anomaly of the zonal average. To that end we will consider two variables related to SAM; the zonal component of the surface wind $\mathrm{u}(10$ m) (from hereafter U10) and the height at $300 \mathrm{hPa}$. The data used for this analysis will be discussed in Section 2. In Section 3, we present the surface wind changes over a period of 36 years, from 1964-1999, and a similar analysis will be shown for the heights $(300 \mathrm{hPa})$ in Section 4 . Finally, conclusions and discussions are in Section 5.

\section{Data and Methods}

We are using three data sets: the ERA40 reanalysis [19], which has been described by Marshall3] as providing a reliable representation of the Southern Hemisphere high latitude atmospheric circulation variability, and two runs of the GFDL global atmosphere and land model, "AM2.1" [20]). The AM2.1 simulations are 135 year runs (18702004) consisting of 10 ensemble members using the same changes in forcing functions, but with sea surface temperatures (SSTs) and sea ice prescribed at observed values. "GFDL_A" runs include only observed SST variability while gas concentrations are fixed to their pre-industrial levels. In the "GFDL_B" runs, all the radiative gases and ozone variability are included. The differences between the GFDL all-forcing (GFDL_B) and the GFDL no forcing (GFDL_A) simulations are mainly the effect of the stratospheric ozone variability that was included in GFDL_B but not in GFDL_A scenarios. Greenhouse gases trends that also were included in $\mathrm{B}$, but not in A, do not significantly impact results because both cases incorporate the same SST variability that reflects most of the changes due to greenhouses gases. The difference between the two atmospheric models' results, GFDL_AM2.1 B (10 member ensemble) and GFDL AM2.1 A (10 member ensemble), will therefore illustrate the effects of ozone variability and change produced by greenhouse gases other than the changes in SST.

Most of the temperature trends in T_polar and $T_{-}$ equator, are probably due to the effects of global warming and ozone depletion. However to prove it from observations requires some assumptions about the data used. First, the ERA40 data to be used before the late seventies are quite unreliable concerning the quality of data over 
the Southern Oceans. However we will use the reanalysis since the early sixties in order to have enough data (close to forty years) for the polar stratospheric and equatorial surface temperature trends to be clear. As previously stated, we try to estimate how much of the change in circulation was affected by polar stratospheric or equatorial temperatures changes, and leave the cause of the temperature changes for the discussion. We assume here that the ERA40 reanalysis is a self-consistent system regardless what process that produced the observed trends in the data sets.

Second, although both GFDL simulations: GFDL_B and GFDL_A used the same atmospheric model and the same time varying SST's, the runs of GFDL_B have variability of greenhouse gases and ozone concentrations whereas the GFDL A runs have all the concentrations fixed to climatological values. Since one of the models has a trend in the stratospheric temperatures (GFDL_B) and the other one does not (GFDL_A), the comparison of both solutions is appropriate to answer the question of how much T_polar and T_equator could control the changes of the south hemisphere circulation. Each simulation is analyzed with its own changes in temperature and resulting self-consistent changes in circulation. However it cannot be concluded that changes observed on GFDL_B are only due to Ozone depletion, absent in the GFDL_A runs. Because GFDL_B has also changes in greenhouse gases and may have some effects in the stratospheric temperatures as well.

The period used is 36 years from 1964 to 1999 (similar to that used in [3]). The method used is very simple:

1) We take the difference of monthly climatology between the last 18-year period (1982-1999) and the period from 1964-1981 as the measure of the climate change that should be explained, for summer months (NDJFMA) and winter months (MJJASO).

2) We carry out a regression of the variables (1964-1999) $\mathrm{U} 10$ and the $300 \mathrm{hPa}$ heights (Z300) with two zonally averaged temperatures; one stratospheric at polar latitudes and the other at low levels in the equatorial region. The time series are divided into summer months and winter months. The temperatures are defined as follows: the zonally averaged polar stratospheric temperature at $150 \mathrm{hPa}$ averaged from $70 \mathrm{~S}$ $80 \mathrm{~S}$ (hereafter T_polar), and the zonally averaged equatorial temperature from $5 \mathrm{~S}-5 \mathrm{~N}$ at $850 \mathrm{hPa}$ (hereafter T_equator). These two temperatures are proxies for the effect of ozone depletion (T_polar) and global ocean warming ( $T$ _equator). The zonally averaged temperature minimizes decadal and interannual variabilities, but does not completely remove them. Note that T_equator is not SST but the atmospheric temperature at $850 \mathrm{hPa}$. Although T_equator has much of the information from the SST, it allows more degrees of freedom between the two model simulations.

3) The monthly climatological mean has been removed from both temperature proxies, $T \_$polar and $T \_$equator. Both time series have a linear trend for the last part of the century, which is more obvious for $T \_$polar in the summer season. An effort has been made to decorrelate these time series (as described in the appendix) to separate their effects in the atmospheric circulation.

4) To maintain their identity, a linear regression was performed with each individual time series on the U10 wind velocity and the height Z300, rather than using a multiple regression (since in this case for the decorrelated variables it would render the same result).

5) To complete the methodology, we make a simple estimate of how well the regression explains the difference in the monthly climatology by calculating the correlation between both patterns. Obviously, the correlation could be positive (in phase) between the climate change and the regression or negative (out of phase). To create a measure of how well the regression matches the climate change, we define the positive correlation as a measure of "control" (if the correlation is negative we consider it zero or "no control"). By this method we quantify how much control $\mathrm{T}$ polar or $\mathrm{T}$ _equator has in explaining changes in climatology.

Figure 1 shows the normalized (by one standard deviation) T_polar and T_equator for the ERA40 reanalysis and both GFDL ensembles runs. It is easy to identify a negative trend in T_polar and a positive trend in T_equator. Also note the difference between T_polar in GFDL $\mathrm{B}$, which shows a negative temperature trend, and $\mathrm{GFDL}^{-}$ A with large variability but no apparent trend. (It should be pointed out that, although the figures for $\mathrm{T}$ polar ERA40 and GFDL_B look very similar, the actual amplitude of the anomaly for the ERA40 is more than double that simulated by GFDL runs. Probably because the GFDL runs have very few stratospheric levels). In contrast, in the right column, T_equator values for the three data sets are very similar, because they are forced with very similar SSTs.

\section{Symmetric and Asymmetric Components of $\mathrm{U} 10$}

\subsection{Changes in the Symmetric Component}

Large anomalies in the strength of the stratospheric polar jet are followed by persistent anomalies in the tropospheric annular mode [21]. Several idealized models have also shown a poleward shift of surface westerlies in direct response to stratospheric winds [22]. More recently, [23]) suggested that a possible link between the stratospheric and tropospheric changes is the fact that 
Zonal Temperature: Polar (150hPa, 70S-80S) and Equatorial (850hPa, 5S-5N)

Anomalies from the monthly climatological mean normalized by theil STD

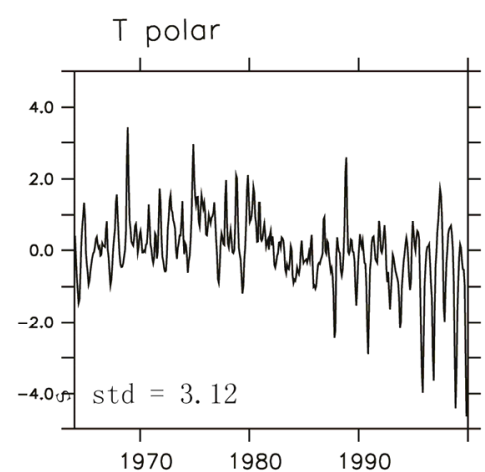

ERA40

$T$ equatorial
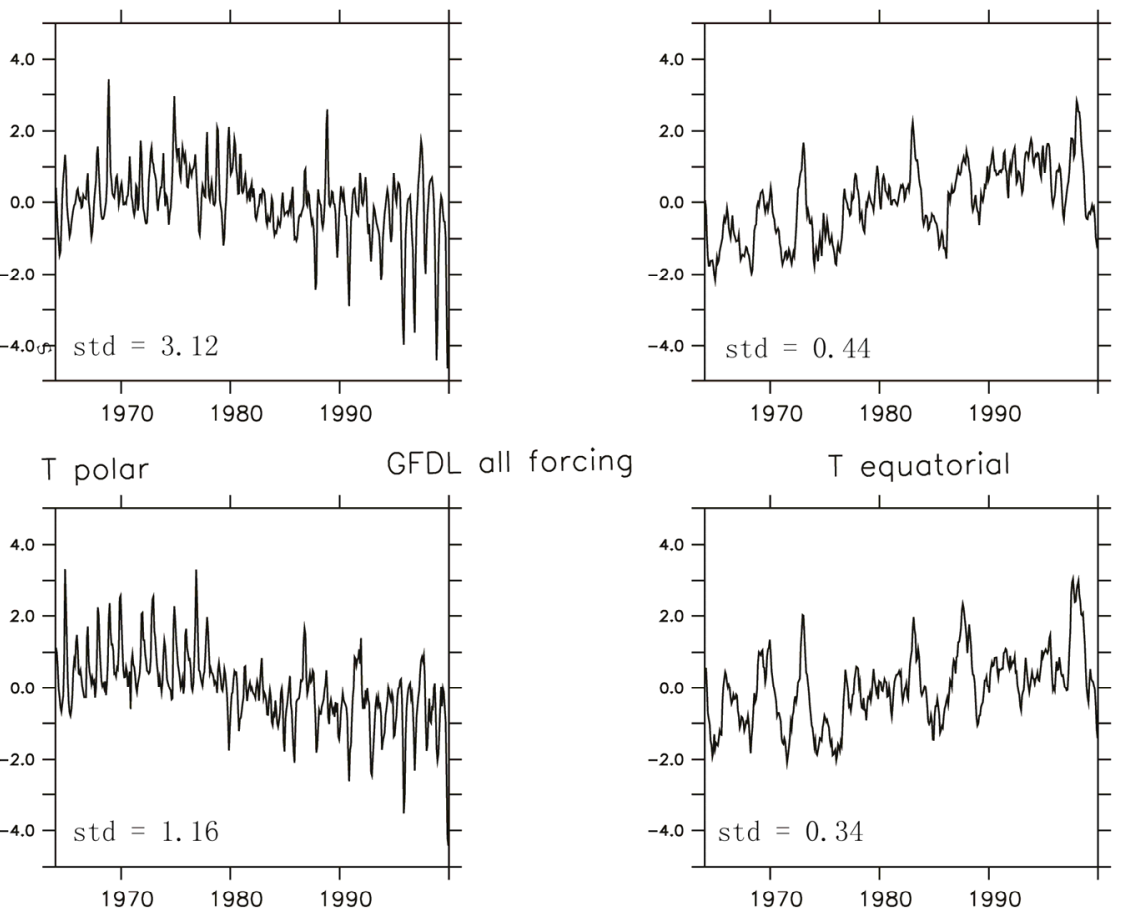

T equatorial

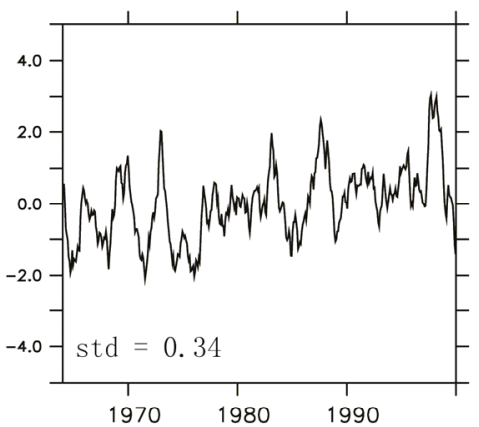

$T$ polar GFDL no forcing

T equatorial
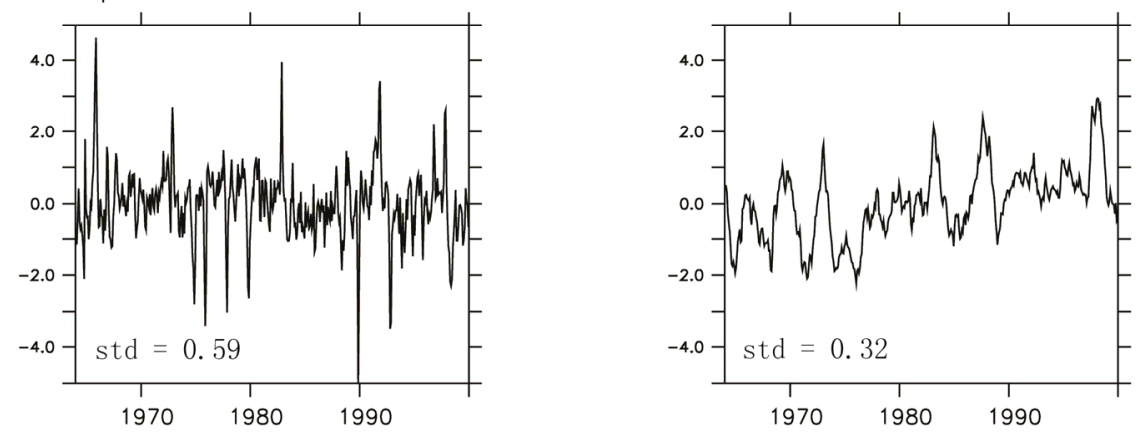

Figure 1. The time series of zonal averaged temperatures, normalized by one standard deviation (STD). Left panels: the lower stratosphere temperature averaged from $70 \mathrm{~S}-80 \mathrm{~S}$ at $150 \mathrm{hPa}$ (T_polar). Right panels: the zonal averaged lower level atmosphere equatorial temperature averaged from $5 \mathrm{~S}-5 \mathrm{~N}$ at $850 \mathrm{hPa}$. The first row is for the reanalysis ERA40, the middle row for GFDL ensemble runs with all forcing, and the lower row is for the GFDL no forcing run.

increasing the stratospheric/upper tropospheric winds increases the eastward phase speed of tropospheric eddies and displaces the region of subtropical wave breaking poleward. This shifts the eddy momentum fluxes poleward, as well as the surface westerlies that are maintained by these momentum fluxes [7] (It should be note that the poleward displacement observed for the surface winds in summer months is only a couple of degrees latitude).

Our definition of the zonally symmetric component of the variables treated here follows the commonly used definitions:
The zonally symmetric of the variable $\mathrm{Z}$ is

$$
\langle\mathrm{Z}(\mathrm{y}, \mathrm{z}, \mathrm{t})\rangle_{\text {sym }}=\text { zonal average of }(\mathrm{Z}(\mathrm{x}, \mathrm{y}, \mathrm{z}, \mathrm{t}))
$$

And the asymmetric part of $Z$ is:

$$
\left.\mathrm{Z}_{\text {asy }}=\mathrm{Z}(\mathrm{x}, \mathrm{y}, \mathrm{z}, \mathrm{t})-<\mathrm{Z}(\mathrm{y}, \mathrm{z}, \mathrm{t})\right\rangle_{\text {sym }}
$$

It is well known that the climatic change of the zonally symmetric component of the U10 wind has a large seasonal variability-the variability is very large in late spring and summer and very small the rest of the year $[23,24]$. The summer difference of the climatic mean over the late period (1982-1999) and the earlier period (1964-1981) is shown in Figure 2. The two panels in the upper row 


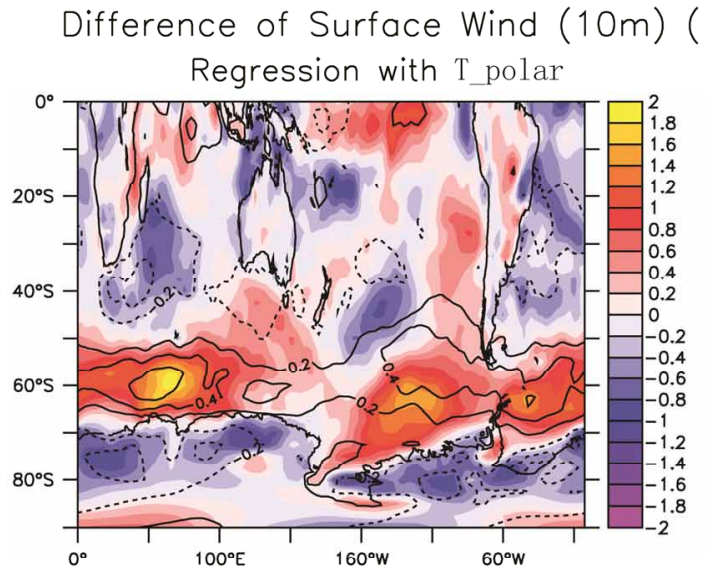

For zonal anomalies

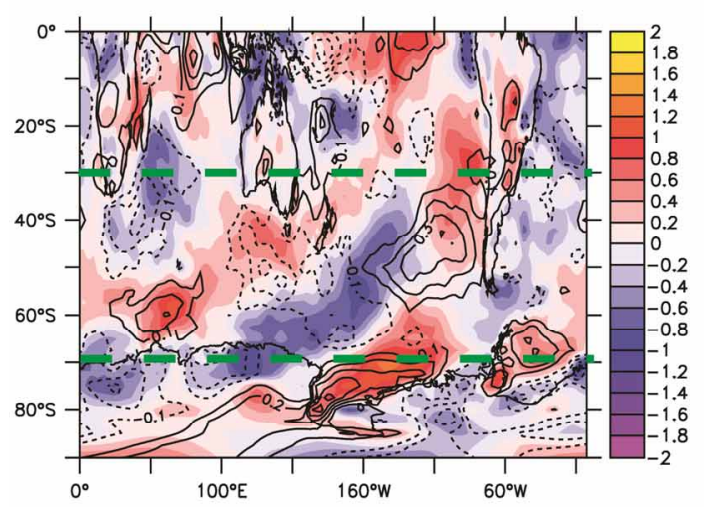

(1982-1999)-(164-1981) Summer ERA4O

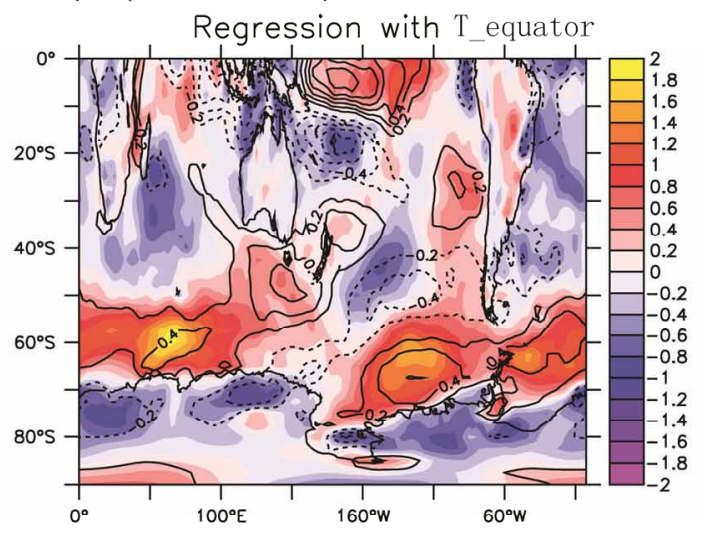

For zonal anomalies

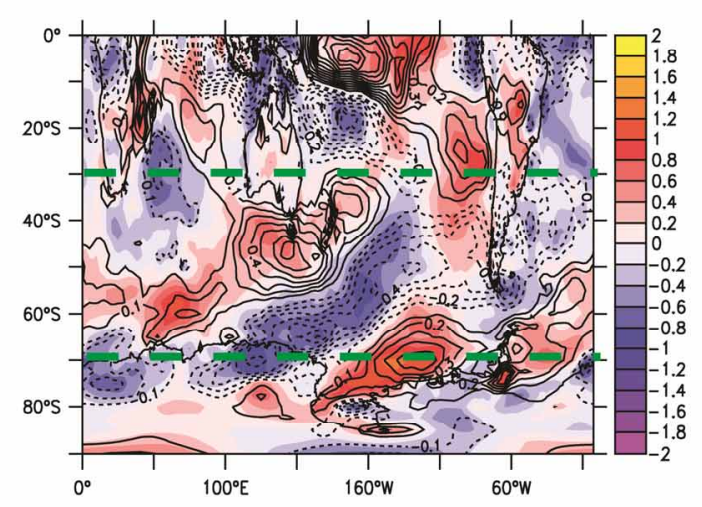

Figure 2. ERA40, Surface wind U10 differences between 1982-1999 and 1964-1981 for the 6 months centered in the austral summer NDJFMA (color). Superposed are regressions (in black contours) of U10 with T_polar (left panels), and with T_equatorial, (right panels). The upper row shows total U10 whereas the zonal anomalies of U10 are shown on the lower row. The green dashed lines show the area in which a similarity test will be performed.

show the climatic difference in color (the same in both panels), with the regressions superposed as black contours for T_polar on the left and with the T_equator on the right. The wind at $10 \mathrm{~m}$ shows a large zonal change around $60 \mathrm{~S}$. The regression with T_polar (left panel) shows a similar behavior, whereas the regression with T_equator (right) shows a significant superposition with the climate change with the asymmetric component of U10 (as can be seen in the lower graphs), but also suggests the zonal mean to be smaller. In contrast, for the zonal anomaly only (lower panels), the climatic difference of the asymmetric component of the wind is clearly better represented by the regression with $\mathrm{T}$ _equator.

By splitting the surface westerly wind into its zonally symmetric component and the asymmetric part, we can evaluate the effects of both the upper stratospheric temperature anomaly and the surface equatorial temperature on each component. Figure 3 shows the zonally symmetric component of the surface westerlies for summer, its climatic change, and the regression of this component with T_polar and T_equator. The climate change of U10 is much larger in the ERA40 reanalysis than the model simulation (GFDL_B), and the response is quite linear with the stratospheric temperature forcing (as previously mentioned, the ERA40 T_polar is close to double the temperature in the GFDL_B runs (e.g., [18]). For both ERA40 and GFDL_B, regression with T_polar better describes the climatic change. Moreover, the fact that GFDL_A does not show any significant climate change confirms the fact that the zonal mean surface westerlies are controlled mainly by ozone depletion that mostly produces the stratospheric temperature anomalies [18]. It should be noted that the responses to $\mathrm{T}$ equator for GFDL_B and GFDL_A are similar-although small, they tend to be out of phase with observed climatic change of U10. [18] find a similar, but smaller, response in runs with greenhouse gas changes that do not include ozone variability. Changes in upper tropospheric effects from $\mathrm{CO}_{2}$ and other gases may also influence the circulation in a manner similar to the ozone depletion, increasing the 

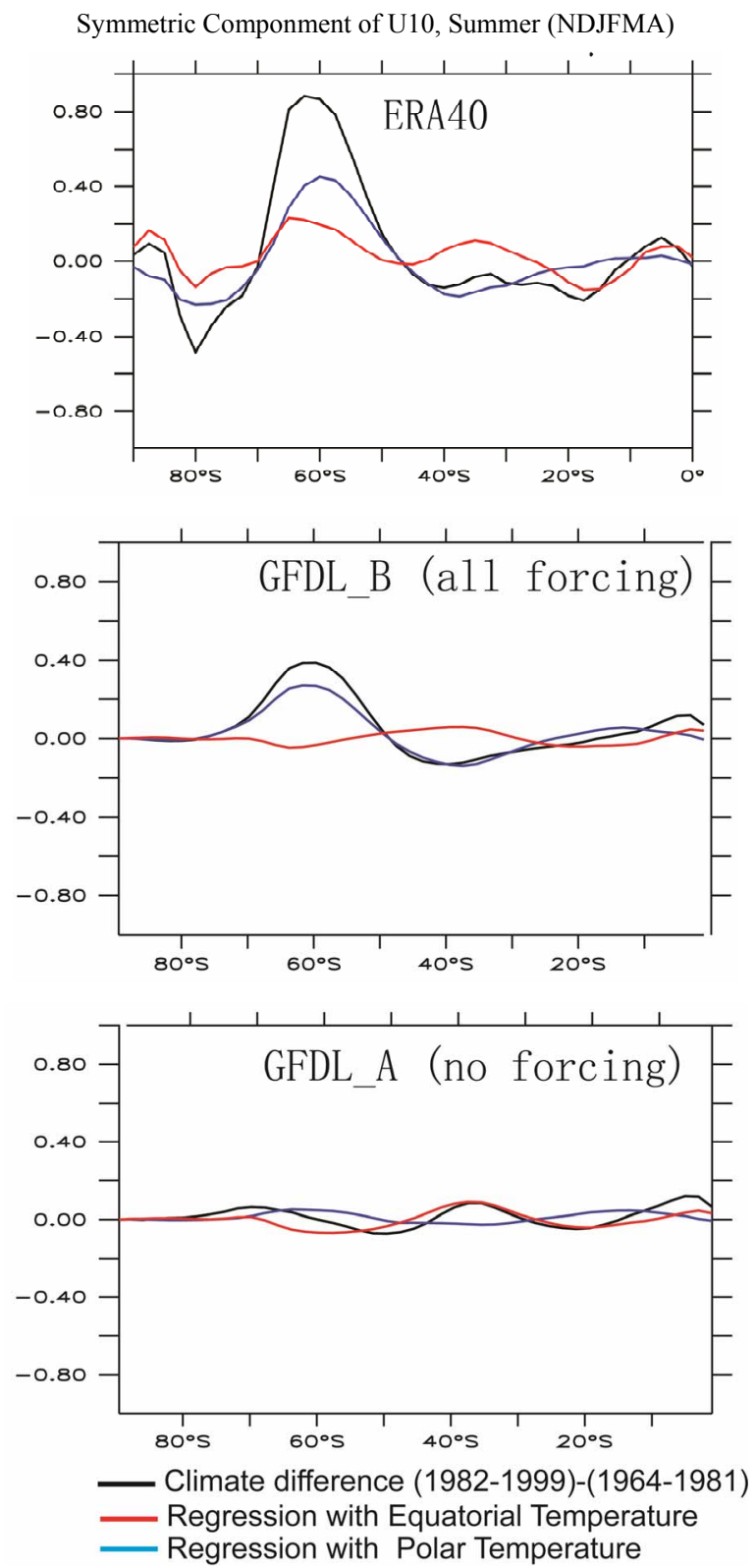

Figure 3. Zonal average of U10, for the summer period. The eighteen year difference (black) and both the regressions: with $T$ _polar (in blue) and $T$ _equator (in red). The upper panel is for ERA40, the middle panel for GFDL_B, and the lower panel for GFDL_A.

surface zonal winds in sub-polar latitudes (as pointed out by [18], to a much weaker degree than the effect of ozone trends).

\subsection{Changes in the Asymmetric Component of U10}

The asymmetric component of U10 for summer, shown in the lower row of Figure 2, shows a very strong similarity between the climatic change and the regression with $T$ _equator. It seems that, in the summer season, the zonally symmetric component is controlled more by variability in T_polar, whereas the asymmetric component is explained by the regression with $T_{-}$equator. In order to quantify the role of each regression in explaining the climatic difference patterns, we define a control parameter. This control parameter is defined as the positive correlation between the difference pattern and the regression pattern over a specific region (in particular from 30S to $70 \mathrm{~S}$ shown as green dashed lines in Figure 2). Before showing the correlation, let us review the patterns for the winter season shown in Figure 4. As previously mentioned the total U10 in winter, exhibits large positive and negative regions, but a small zonally symmetric component. The asymmetric anomaly seems as large as in the summer months. Again the most relevant feature is the coherence between the climatic difference anomaly and the regression with $\mathrm{T}$ _equator.

We can summarize the results by calculating the correlation between the two regressions and the climatic difference over the area shown between the green lines of Figure 2. The control parameters for summer and winter are shown in Figure 5 for the three data sets. There is great consistency between the reanalysis and the two model solutions. The outlier seems to be GFDL_B for the summer season, but in general there is a very good agreement among the figures, particularly for the winter season. The averaged calculated correlation for each member that composed the ensemble (Figure 5) of GFDL_B runs is shown in Table 1. Values for GFDL_A are not shown since only one major forcing was acting for that case Note that each individual correlation between the climate change and the regression is a nonlinear function for each independent member and its average may not coincide with the ensemble mean correlation. The results are fairly consistent among the members. Which is remarkable given that the forcing for stationary waves in the South Hemisphere is very weak; as a consequence the variability between each member is considerable. Because these asymmetries in the surface westerly wind should also be manifested in height anomalies, we next apply the same analysis to that field.

\section{Asymmetric Component of the Geo-Potential Heights 300 hPa}

The climatic change of the zonal anomalies of the 300 $\mathrm{hPa}$ height field for the ERA40 and both GFDL simulations are shown in Figure 6 for the summer season. As in Figure 2, we show the climatic difference in both panels for the same row and the two regressions of that field, with T_polar on the left and T_equator on the right. The main characteristic of the response seems to be a wave train of Rossby waves that emanate from the Indian Ocean and propagate south east of the Pacific Ocean that 


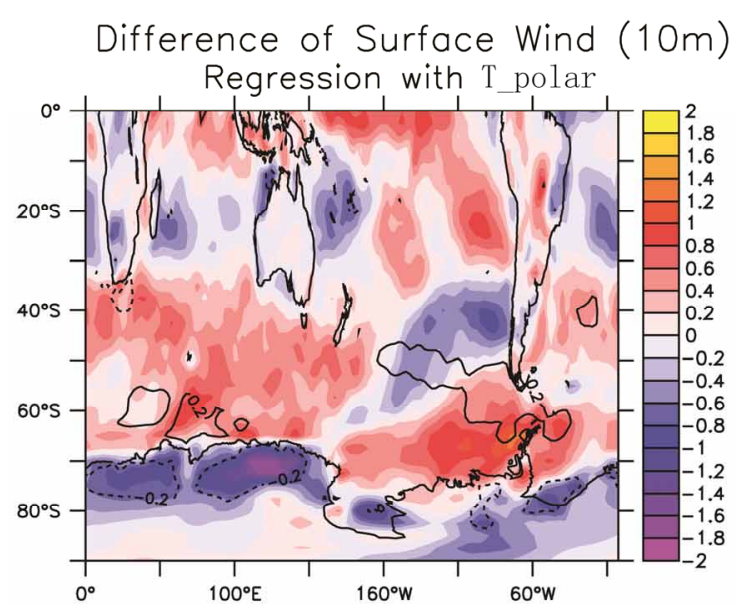

For zonal anomalies

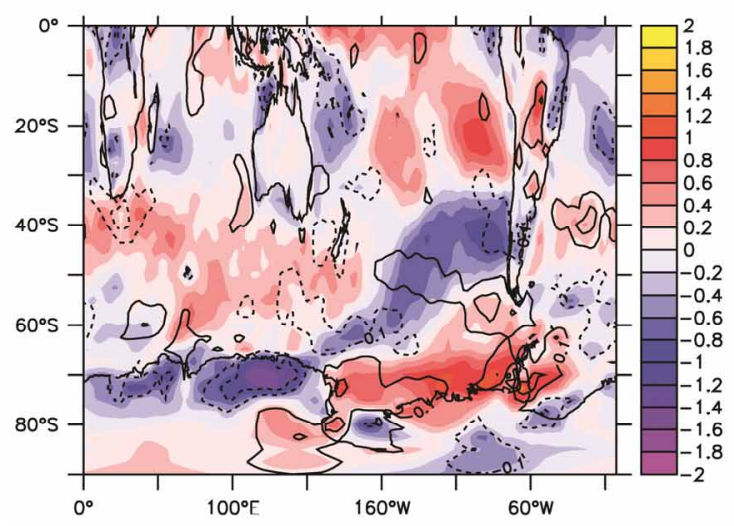

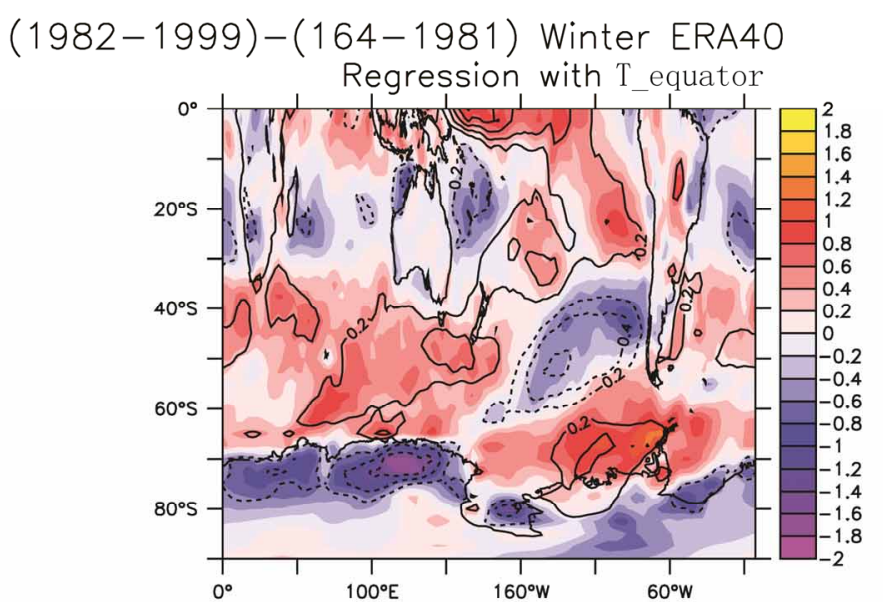

For zonal anomalies

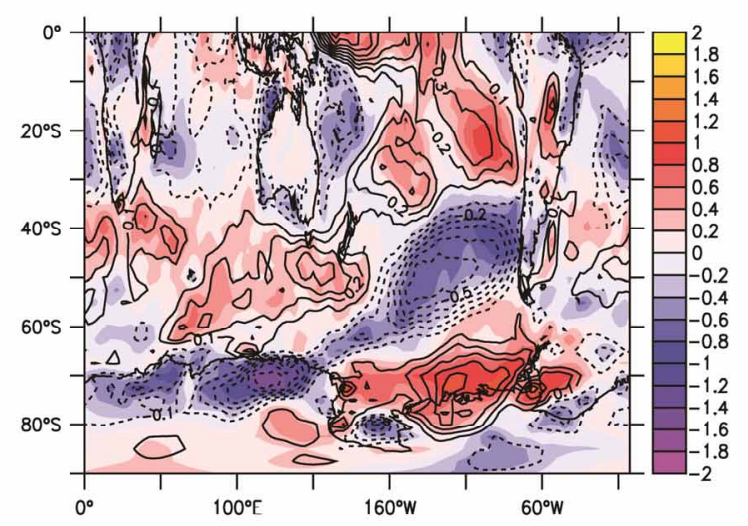

Figure 4. The same as in Figure 2, but for the 6 months centered in the austral winter.

Control Diagram of Polar and Equatorial Temperatures on Heights.
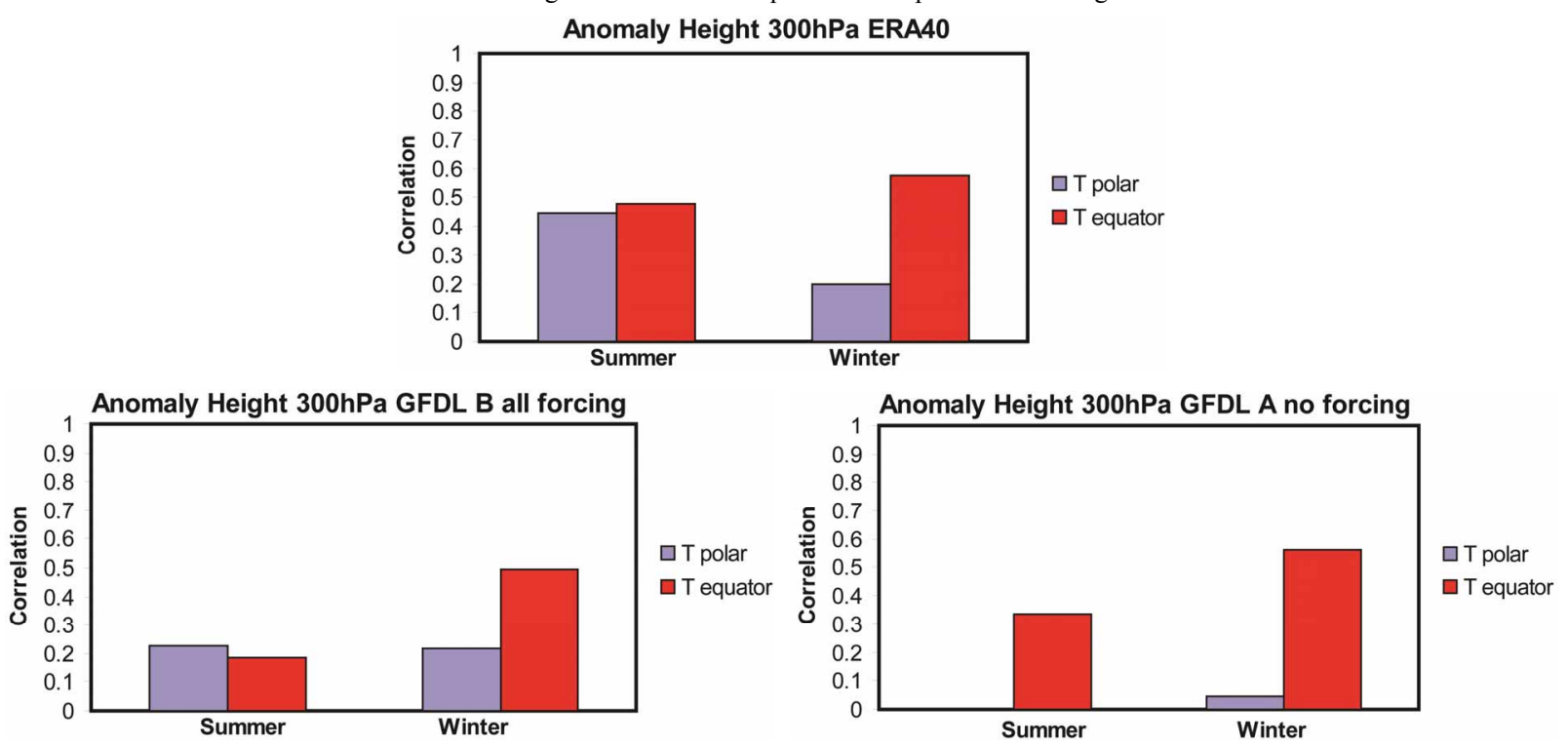

Figure 5. The control diagram summarizing how much the regressions with $T$ _polar (blue) and $T$ _equator (red) explain the climate differences for each season. Each dataset is shown as in Figure 3. 

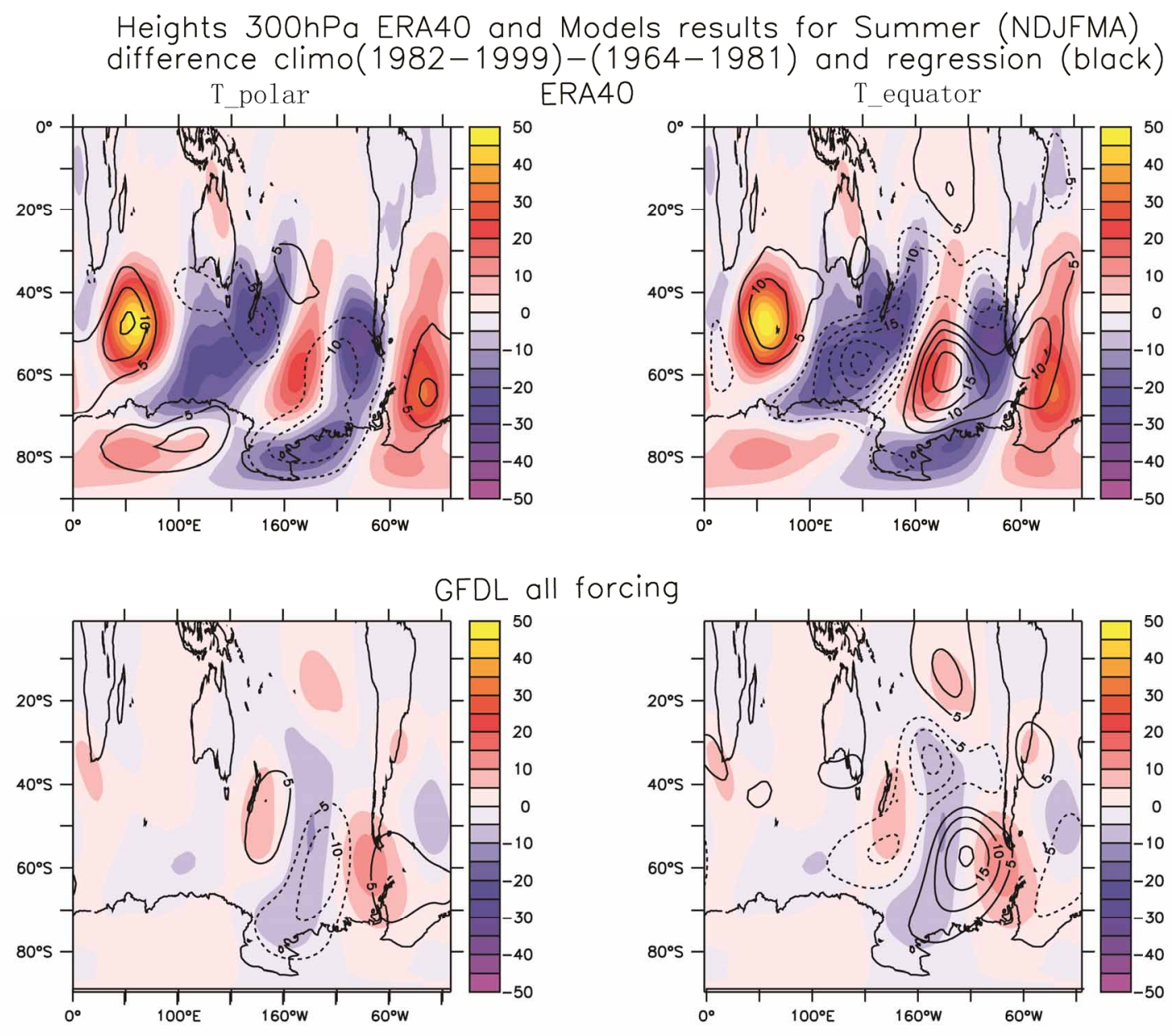

GFDL no forcing
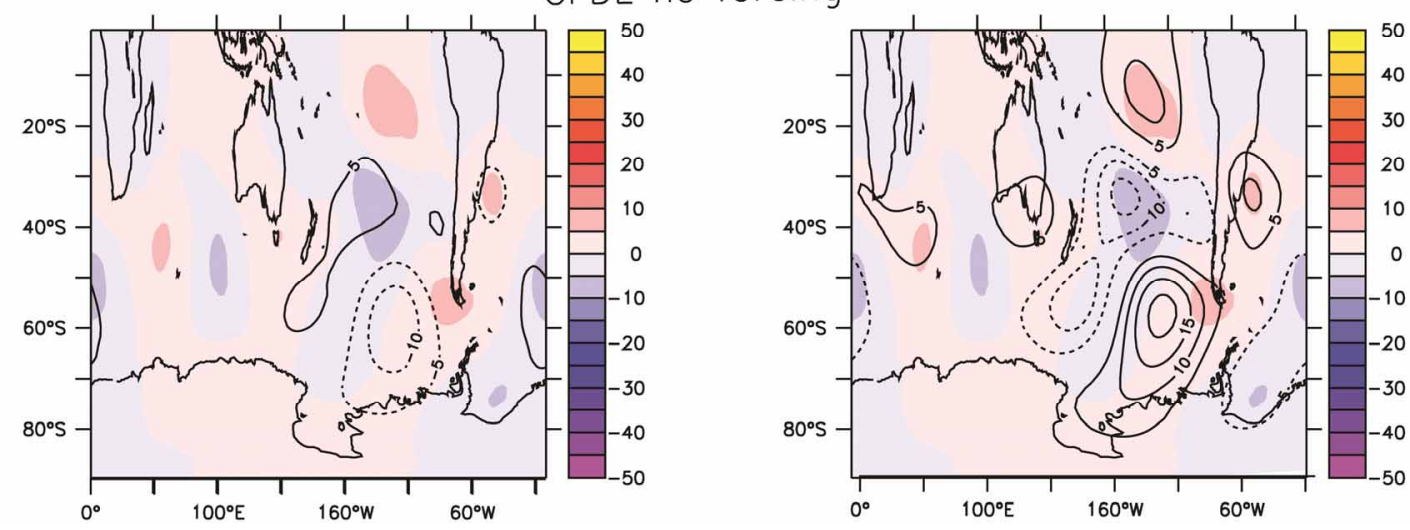

Figure 6. The zonal anomalies for the $300 \mathrm{hPa}$ heights are shown for the summer period. The climate differences are shown in color. As in Figure 2, the regressions of $T$ _polar and $T$ equator are shown in black contour. The upper row is for ERA40, the middle row for GFDL_B and the lower row for GFDL_A.

is clearly seen in the ERA40, but is more weakly exhibited in the other two simulations. Note that while both regressions reproduce some features of the difference fields for the ERA40, the GFDL simulations tend to be consistent with ERA40 for the regression with T_equator, in particular a height anomaly center around $110 \mathrm{~W}$ and
60S. This pattern also seems to be characteristic of an interannual pattern known as the PSA [17]. A superficial inspection suggests that the combination of both regressions could describe the summer difference pattern well. However, for the winter patterns shown in Figure 7, the $\mathrm{T}$ _equator regression practically reproduces the entire- 
Heights 300hPa ERA40 and Models results for Winter (MJJASO) difference climo 1982-1999)-(1964-1981) and regression (black)

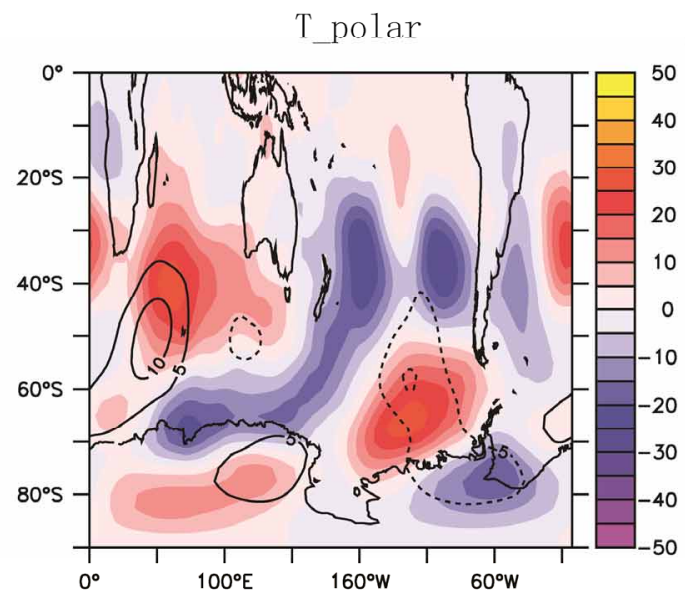

ERA40
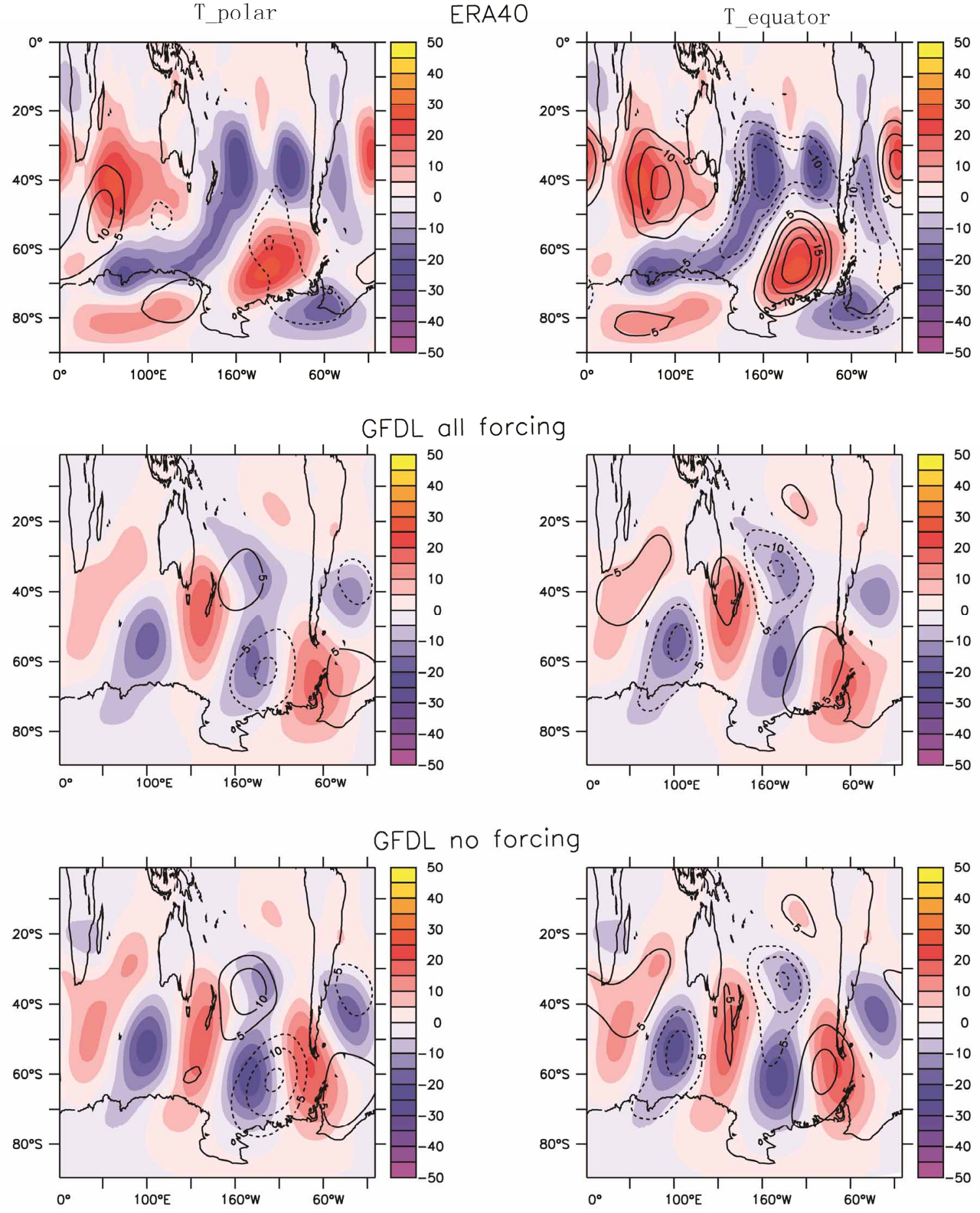

Figure 7. The same as in Figure 6, but for the winter period.

difference pattern in the ERA40 reanalysis, and shows weaker but still good correlation with the differences in the two GFDL simulations. In contrast, the T polar regression tends to be quite out of phase with all three difference patterns.
The results of Figures 6 and 7 can be summarized by calculating the correlation pattern as has been shown for U10 (Figure 5). The control parameter shown in Figure 8 contains clearly what we have seen in the previous figures. The control is shared between $T \_$polar and 
Control Diagram of Polar and Equatorial Temperatures on Heights.
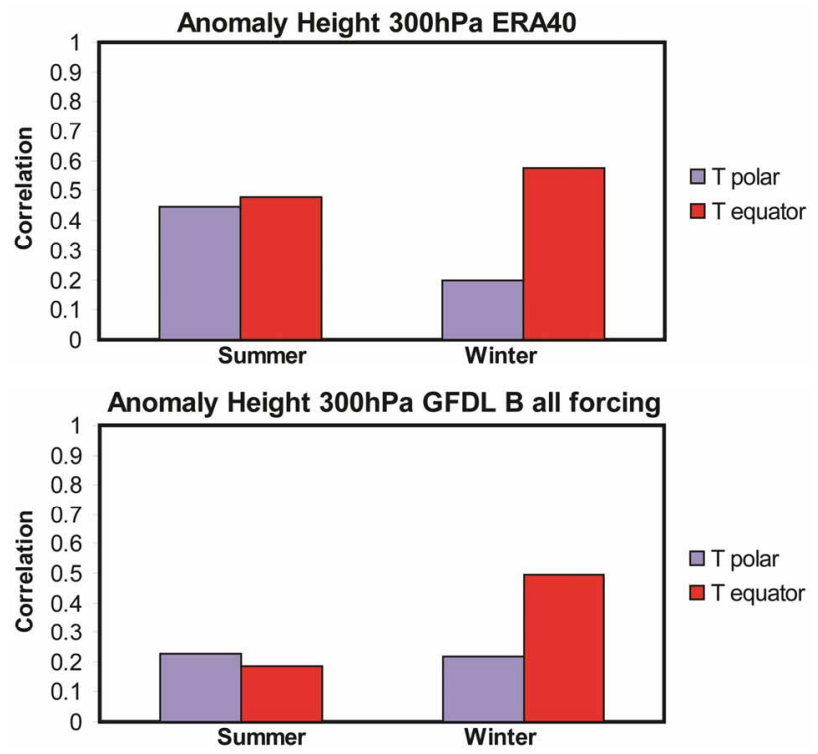

Anomaly Height 300hPa GFDL A no forcing

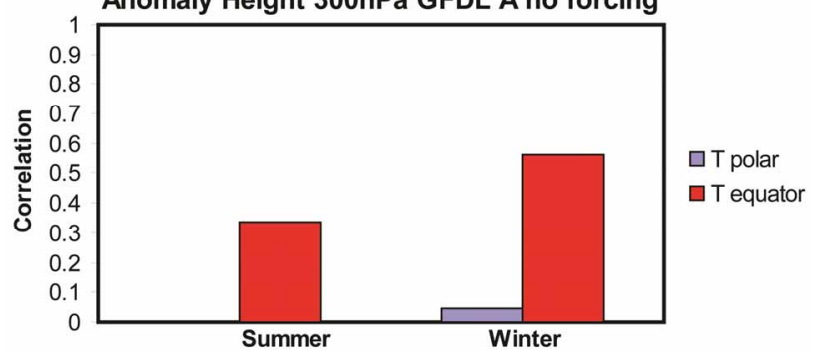

Figure 8. The control diagram for the asymmetric component of 300 hPa Height (see Figure 5).

$\mathrm{T}$ _equatorial for the summer period and T_equator exerts more control for the winter season. These results are corroborated for the ERA40 as well as both GFDL simulations. The averaged controls for the individual members for GFDL_B also exhibit a consistent pattern (see Table 1). It should be pointed out that the climate difference response for the ensemble mean seems rather weak compared with the ERA40 response. An inspection of the height response for each individual member shows that, although they consistently reproduce a height anomaly at the South-East Pacific Ocean (some of them as large as the ERA40 response), the individual centers vary as much as 50 degrees longitude from each other, producing a weaker ensemble averaged.

One feature that clearly stands out in all three datasets is a Rossby wave train from the Indian Ocean to the southeast Pacific Ocean that ends in a blocking high similar to the summer pattern of Figure 6. The zonally asymmetric climate change signal in the SH troposphere is dominated by two quasi-stationary anticyclones south of the Indian Ocean and south-eastern Pacific Ocean. These patterns are very similar to those found by HR2010. As has been discussed by HR2010 and others,
Table 1. Values of the individual correlations for members of GFDL All forcing. Individual correlation of $\triangle \mathrm{Z300}$ and $\Delta \mathrm{U} 10$ for regressions of $\mathrm{T} \_$polar and $T$ _equator.

\begin{tabular}{|c|c|c|c|c|}
\hline$\Delta \mathrm{ZZ} 300$ & Member & \multicolumn{2}{|c|}{ Summer } & Winter \\
\hline \# & $\mathrm{T} \_$polar & T_equator & T_polar & T_equator \\
\hline 1 & 0.3096 & 0.2741 & 0.176 & 0.364 \\
\hline 2 & 0.090 & 0.1065 & -0.0354 & 0.180 \\
\hline 3 & -0.001 & 0.248 & -0.057 & 0.305 \\
\hline 4 & 0.2859 & 0.061 & 0.421 & 0.414 \\
\hline 5 & 0.062 & 0.107 & 0.095 & 0.151 \\
\hline 6 & 0.069 & 0.278 & 0.138 & 0.167 \\
\hline 7 & 0.148 & 0.327 & -0.022 & 0.293 \\
\hline 8 & 0.299 & -0.153 & 0.161 & 0.458 \\
\hline 9 & 0.142 & 0.259 & -0.053 & 0.280 \\
\hline 10 & 0.225 & 0.094 & -0.275 & 0.426 \\
\hline$\Delta \mathrm{U} 1$ & Member & \multicolumn{2}{|c|}{ Summer } & Winter \\
\hline \# & $\mathrm{T} \_$polar & T_equator & T_polar & T_equator \\
\hline 1 & 0.619 & 0.372 & 0.331 & 0.520 \\
\hline 2 & 0.325 & 0.395 & 0.179 & 0.576 \\
\hline 3 & 0.072 & 0.229 & -0.164 & 0.635 \\
\hline 4 & 0.460 & 0.107 & 0.616 & 0.586 \\
\hline 5 & 0.360 & 0.259 & 0.560 & 0.196 \\
\hline 6 & 0.170 & 0.546 & 0.601 & 0.133 \\
\hline 7 & 0.213 & 0.402 & 0.133 & 0.487 \\
\hline 8 & 0.646 & -0.176 & 0.538 & 0.658 \\
\hline 9 & 0.394 & 0.366 & -0.067 & 0.638 \\
\hline 10 & 0.247 & 0.304 & -0.273 & 0.883 \\
\hline
\end{tabular}

these patterns are a response to the Indian Ocean warming and the interannual-decadal variability of the equatorial Pacific Ocean.

Although the work presented here focuses on seasonal data, the trend in the anticyclones can be linked to blocking of the high frequency eddies. [25] analyzed SH blocking events lasting 5 days or longer, and found that persistent geopotential height anomalies occurred throughout the year south of New Zealand, in a region east of the Indian Ocean. A second region was also evident in the south-east Pacific Ocean, corresponding to the anticyclone location which was much more significant in winter season and very similar to that shown in Figure 7.

\section{Summary and Discussion}

The consistency of the results obtained with the ERA40 and both GFDL solutions makes the conclusions rather 
robust. Our results show that the zonally symmetric surface winds in the summer period, over the last decades of the past century, have a considerably enhanced intensity in high latitudes of the SH (around 60S as shown in Figure 3), consistent with previously reported results $[1,2]$, among others). Our analysis also suggests that the stratospheric temperature trend ( $T \_$polar) is the major contributor to that change. Moreover, the symmetric component of U10 displays a similar, although weaker, maximum for the GFDL_B solutions, but a very weak maximum for the GFDL_A runs. This difference in model response reaffirms that the trend of T_polar (ozone depletion) is the main cause of the drifting of the zonal winds to sub polar latitudes.

The response expected from the surface equatorial temperatures (T_equator), although being consistent between the two GFDL runs, disagrees with the ERA40 analysis over the sub-polar regions. From both GFDL runs, it appears that the global ocean warming solution can not by itself produce a sustainable sub-polar drift. It should be remembered that the trend in ocean temperature, although it is the largest effect of the increase of greenhouses gases, is not the only one. Changes in upper tropospheric effects from $\mathrm{CO}_{2}$ and other gases may also influence the circulation in a matter similar to the ozone depletion, increasing the surface zonal winds in sub polar latitudes (as pointed out by [18], to a much weaker degree than the effect of ozone trends).

The climatic change of the asymmetric component of U10 has been found to be large for summer and winter periods. To quantify the response of both regressions, T_polar and T_equator, with the climatic differences, we compute the correlation between both patterns and refer to the positive correlation as "control". In contrast with the findings for the zonally symmetric component, it was found that $\mathrm{T}$-equator exerts a strong control over climatic changes for the asymmetric component of U10 for summer and winter periods. These results are consistent between ERA40, and both GFDL ensembles run. However the stratospheric temperature $T$ polar has some effect, in particular for the summer period. The analysis of the asymmetric component for the $300 \mathrm{hPa}$ Heights has a similar response with respect to the control exerted by $\mathrm{T}$ polar and T_equator as for the surface winds, U10. These results are corroborated for the ERA40 as well as both GFDL simulations.

The zonally asymmetric climate change signal in the SH troposphere is dominated by two quasi-stationary anticyclones south of the Indian Ocean and south-eastern Pacific Ocean. These patterns are very similar to those found by HR2010. This simple analysis tries to suggest that the asymmetric component changes are considerable over the high latitudes of the $\mathrm{SH}$ and are not as much a product of the ozone depletion, which in future climates may recuperate, but are mainly forced by the warming of the global oceans (Indian and Pacific Ocean). This regional ocean forcing tends to project better on the asymmetric component of the high latitude SH circulation. This is mainly because of the response from Rossby waves rays directed to the sub-polar regions [26], in contrast with the more zonally symmetric forcing that stratospheric temperatures produce. These asymmetries, through deflection of storm tracks, modify the sea-ice distribution and change sub-polar ocean currents, with significant implications for future climate.

\section{Acknowledgements}

The author is deeply indebted to Dr. Isaac Held for his valuable comments along this research, also appreciates his comments on the paper as well as Dr. Thomas Delworth and Dr. Silvina Solman that helped clarify the manuscript. Special appreciation to Dr. Roberta M. Hotinski for editing the manuscript. Acknowledgments to ERA-interim project of ECMWF, Dr Fanrong. Zeng and Dr. Andrew Wittenberg for providing data from GFDL models and ERA40 data base and advise on Ferret analysis.

This report was prepared by Isidoro Orlanski under award NA08OAR4320752 from the National Oceanic and Atmospheric Administration, US Department of Commerce. The statements, findings, conclusions, and recommendations are those of the author(s) and do not necessarily reflect the views of the National Oceanic and Atmospheric Administration, or the US Department of Commerce.

\section{REFERENCES}

[1] D. W. J. Thompsonand S. Solomon, "Interpretation of Recent Southern Hemisphere Climate Change," Science, Vol. 296, No. 5569, 2002, pp. 895-899.

[2] C. Archer and K. Caldeira, "Historical Trends in the Jet Streams," Geophysical Research Letters, Vol. 35, No. 8, 2008, Article ID: L08803, http://dx.doi.org/10.1029/2008GL033614

[3] G. J. Marshall, "Trends in the Southern Annular Mode from Observations and Reanalysis," Journal of Climate, Vol. 16, No. 24, 2003, pp. 4134-4143.

[4] Q. Fu, J. C. Wallace and J. Reitchler, "Enhanced MidLatitude Tropospheric Warming in Satellite Measurements," Science, Vol. 312, No. 5777, 2006, p. 1179. http://dx.doi.org/10.1126/science.1125566

[5] Y. Hu and Q. Fu, "Observed Poleward Expansion of the Hadley Circulation Since 1979," Atmospheric Chemistry and Physics, Vol. 7, 2007, pp. 5229-5236. http://dx.doi.org/10.5194/acp-7-5229-2007

[6] J. Lu, G. A. Vecchi and T. Reichler, "Expansion of the Hadley Cell under Global Warming," Geophysical Research Letters, Vol. 34, 2007, Article ID: L06805. 
http://dx.doi.org/10.1029/2006GL028443

[7] C. Vera, G. Silvestri, B. Liebmann and P. Gonzalez, "Climate Change Scenarios for Seasonal Precipitacion in South America from IPCC-AR4 Models," Geophysical Research Letters, Vol. 33, 2006, Article ID: L13707.

[8] S. Solman and I. Orlanski, "Subpolar High Anomaly Preconditioning Precipitation over South America," Journal of the Atmospheric Sciences, Vol. 67, No. 5, 2010, pp. 1526-1542. http://dx.doi.org/10.1175/2009JAS3309.1

[9] B. L. Preston and R. N. Jones, "Climate Change Impacts on Australia and the Benefits of Early Action to Reduce Global Greenhouse Gas Emissions,” Report CSIRO, 2006.

[10] H. D. Pritchard, et al., "Antarctic Ice-Sheet Loss Driven by Basal Melting of Ice Shelves," Nature, Vol. 484, 2012, pp. 502-505. http://dx.doi.org/10.1038/nature10968

[11] D. G. Vaughn, G. J. Marshall, W. M. Connolley, C. Parkinson, R. Mulvaney, D. A. Hodgson, J. C. King, J. C. Pudsey and J. Turner, "Recent Rapid Regional Climate Warming in the Antarctic Peninsula," Climate Change, Vol. 60, 2003, pp. 243-274.

[12] J. Turner and J. Overland, "Contrasting Climate Change in the Two Polar Regions," Polar Research, Vol. 28, No. 2, 2009, pp. 146-164. http://dx.doi.org/10.1111/j.1751-8369.2009.00128.x

[13] J. Turner, T. A. Lachlan-Cope, S. Colwell, G. J. Marshall and W. M. Connolley, "Significant Warming of the Antarctic Winter Troposphere," Science, Vol. 311, No. 5769, 2006, pp. 1914-1917. http://dx.doi.org/10.1126/science.1121652

[14] E. J. Steig, D. P. Schneider, S. D. Rutherford, M. E. Mann, J. C. Comiso and D. T. Shindell, "Warming of the Antarctic Ice-Sheet Surface Since the 1957 International Geophysical Year," Nature, Vol. 1457, No. 7228, 2009, pp. 459-463. http://dx.doi.org/10.1038/nature07669

[15] R. W. Hobbs and M. N. Raphael, "Characterizing the Zonally Asymmetric Component of the SH Circulation," Climate Dynamics, Vol. 35, 2010, pp. 859-873.

[16] N. Mathewman and G. Magnusdottir, "Clarifying Ambiguity in Intraseasonal Sothern Hemisphere Climate Modes during Austral Winter," Journal of Geophysical Research, Vol. 113, No. D7, 2012, Article ID: D03105.

[17] K. C. Mo and J. N. Paegle, "The Pacific-South American
Modes and Their Downstream Effects," International Journal of Climatology, Vol. 21, No. 10, 2001, pp. 1211-1229.

[18] L.-M. Polvani, D. W. Waugh, G. J. P. Correa and S.-W. Son, "Stratospheric Ozone Depletion: The Main Driver of Twentieth-Century Atmospheric Ciruclation Changes in the Southern Hemisphere," Journal of Climate, Vol. 24, 2011, pp. 795-812.

[19] S. M. Uppala, et al., "The ERA-40 Re-Analysis," Quarterly Journal of the Royal Meteorological Society, Vol. 131, 2005, pp. 2961-3012.

[20] J. Anderson, et al., "The New GFDL Global Atmosphere and Landmodel AM2/LM2: Evaluation with Prescribed SST Simulations," Journal of Climate, Vol. 17, 2004, pp. 4641-4673.

[21] D. W. J. Thompson, J. M. Wallace and G. C. Hegerl, "Annular Modes in the Extra-Tropical Circulation, Part II: Trends," Journal of Climate, Vol. 13, 2000, p. 1018.

[22] L. Polvani and P. J. Kushner, "Tropospheric Response to Stratospheric Perturbations in a Relatively Simple General Circulation Model," Geophysical Research Letters, Vol. 29, No. 7, 2002, 18 p. http://dx.doi.org/10.1029/2001GL014284

[23] G. Chen and I. M. Held, "Phase Speed Spectra and the Recent Poleward Shift of Southern Hemisphere Surface Westerlies," Geophysical Research Letters, Vol. 34, No. 21, 2007, Article ID: L21805. http://dx.doi.org/10.1029/2007GL031200

[24] P. Kushner, I. M. Held and T. L. Delworth, "Southern Hemisphere Atmospheric Circulation Response to Global Warming," Journal of Climate, Vol. 14, No. 10, 2001, pp. 2238-2249.

http://dx.doi.org/10.1175/1520-0442(2001)014<0001:SH ACRT $>2.0 . \mathrm{CO} ; 2$

[25] K. E. Trenberth and K. C. Mo, "Blocking in the Southern Hemisphere," Monthly Weather Review, Vol. 113, No. 1, 1985, pp. 3-21.

[26] I. Orlanski and S. Solman, "The Mutual Interaction between External Rossby Waves and Thermal Forcing: The Sub-Polar Region," Journal of the Atmospheric Sciences, Vol. 67, 2010, pp. 2018-2038. 


\section{Appendix}

\section{To Partially Decorrelate the Time Series}

Assume two time series that are slightly correlated, say:

$$
Y=Y(t) \text { and } T=T(t)
$$

The cross-correlation between them is:

$$
C_{Y T}=\sum\left(Y^{\prime} * T^{\prime} /\left((N-1) \sigma_{Y} \sigma_{T}\right)\right)
$$

where $\sigma_{Y}, \sigma_{T}$ are the standard deviations of each function.

$$
\sigma_{U}=\left(\sum(U-\bar{U})^{2} /(N-1)\right)^{0.5}
$$

where $\bar{U}$ is the mean of the variable $U$.

To decorrelate $Y$ with $T$, it is enough to calculate the regression of $Y$ on $T$ as follows:

$$
R_{Y}=\sum\left(Y^{\prime} * T^{\prime} /\left((N-1) \sigma_{T}\right)\right)
$$

Then the decorrelated $Y$ anomaly can be written as:

$$
Y_{d c}^{\prime}=Y^{\prime}-R_{Y} T^{\prime} / \sigma_{T}
$$

It is easy to see the correlation between $T^{\prime}$ and $Y_{d c}^{\prime}$ is equal to zero. However it seems asymmetric: one time series has been modified and the other not. We could apply the same algorithm to both time series to partially decorrelate them. In this case, the correlation between $Y_{d c}^{\prime} T_{d c}^{\prime}$ is not zero, but it is very small.

$$
\begin{gathered}
Y_{d c}^{\prime}=Y^{\prime}-0.5 * R_{Y} * T^{\prime} / \sigma_{T} \\
\mathrm{~T}_{d c}^{\prime}=\mathrm{T}^{\prime}-0.5 * R_{T} * \mathrm{~T}^{\prime} / \sigma_{\mathrm{T}} \\
C_{Y d c T d c}=\sum\left(Y_{d c}^{\prime} * T_{d c}^{\prime} /(N-1) \sigma_{Y d c} \sigma_{T d c}\right) \\
=\left[\sum\left\{Y^{\prime} * T^{\prime}+0.25 *\left(R_{T} R_{Y} / \sigma_{Y} \sigma_{T}\right) * Y^{\prime} * T^{\prime}-0.5 *\left(R_{T} Y^{\prime 2} / \sigma_{Y}+R_{T} Y^{\prime 2} / \sigma_{T}\right)\right\}\right] /\left((N-1) \sigma_{Y d c} \sigma_{T d c}\right)
\end{gathered}
$$

Replacing $R_{T}$ and $R_{Y}$ for their definition $\mathrm{A} 4$, it is easy to show that the last term of $\mathrm{A} 9$ can be written as follows:

$$
\sum 0.5 *\left(R_{T} Y^{\prime 2} / \sigma_{Y}+R_{T} Y^{\prime 2} / \sigma_{T}\right)=\sum\left(Y^{\prime} * T^{\prime}\right)
$$

And the expression in A9 can be reduced to:

$$
C_{Y d c T d c}=0.25 *\left(R_{T} R_{Y} / \sigma_{Y} \sigma_{T}\right) \sum Y^{\prime} T^{\prime} /\left((N-1) \sigma_{Y d c} \sigma_{T d c}\right)
$$

Recognizing that the Standard deviation $\sigma_{Y d c}$ and $\sigma_{T d c}$ can be rewritten as:

$$
\sigma_{Y d c}=\left\{\sum Y^{\prime 2}-R_{Y} Y^{\prime} T^{\prime} / \sigma_{T}+0.25 *\left(R_{Y} / \sigma_{T}\right) \sum T^{\prime 2}\right\} /(N-1)
$$

Using the definitions A2, A3 and A4, A12 can be written as follows:

$$
\sigma_{Y d c}=\sigma_{Y}\left(1-0.75 C_{Y T}^{2}\right)^{0.5}
$$

And similarly for: A13

$$
\sigma_{T d c}=\sigma_{T}\left(1-0.75 C_{Y T}^{2}\right)^{0.5}
$$

Finally, the correlation of the partially decorrelated time series A7-A8

$$
C_{Y d c T d c}=0.25 *\left(C_{Y T}\right)^{3} /\left(1-0.75 C_{Y T}^{2}\right)
$$

shows that for cases in which $\mathrm{C}_{\mathrm{YT}} \sim-0.3$, as in our case,

the time series is very well decorrelated.

$$
C_{Y d c T d c}=-0.0072
$$

